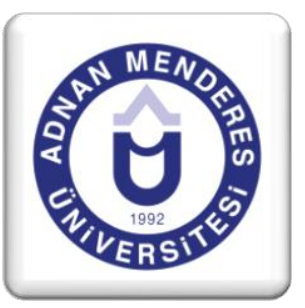

\title{
Türkiye'de Mali Teşvik Sistemi ve Yatırımlara Sağlanan Mali Teşviklerin Değerlendirilmesi
}

Asuman ALTAY ${ }^{1}$, Şahin KARABULUT ${ }^{2}$

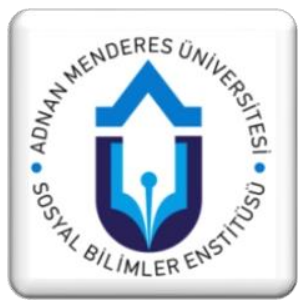

\section{ÖZET}

Devlet tarafından genellikle özel sektöre yönelik alınan mali bir önlem olan mali teşvikler kamu gelirleri üzerinde çoğunlukla önemli bir yük oluşturmaktadır. Devletin kamusal ihtiyaçları karşılamak üzere yaptığı harcamaları finanse etmek için ihtiyaç duyduğu kamusal gelir kaynaklarından yeterince faydalanmamayı kabul etmesinin altında birçok neden yatmaktadır. Mali teşvikler sonucunda özel sektör gelirlerinin artması sonucu daha fazla vergi ödeneceğini ve böylelikle mali teşviklerin kamu gelirlerini azaltması bir tarafa, kamu gelirlerini artırıcı bir özellik göstereceğini varsayan görüşler dahi mevcuttur. Ancak devletin asıl amacının gelirini giderinden fazla tutarak artı bakiye yaratmak (kâr elde etmek) olmaması mali teşvik programlarının belirlenmesi sırasında mali güdülerle hareket edilmediğini ortaya koymaktadır. Bu açıdan mali teşvikler yoluyla ulaşılmak istenilen amaçlar, ülkedeki yatırımların artırılması, ekonomik büyümenin ve kalkınmanın sağlanması, istihdamın artırılması, ekonomiye ilişkin konjonktürel sorunların aşılması, yabancı sermayenin ülkeye çekilmesi gibi çeşitli makroekonomik hedeflerden oluşmaktadır.

Anahtar Kelimeler ; Mali Teşvik, Yatırım, Kalkınma.

Jel Kodlarl ; E62, E22, O23.

\section{Institutional - Financial Dimension and Evaluation of Financial Incentives in Turkey}

\begin{abstract}
Financial incentives, which are usually a financial measure taken by the government towards the private sector, are often a significant burden on public revenues. There are many reasons for the government's acceptance of public income decline. In some cases, more tax will be paid as a result of increased incomes of the private sector along with financial incentives so that fiscal incentives increase public revenues as opposed to reducing public revenues. However, the main purpose of the government is not to keep the income more than the expenditure. Which means that financial incentive programs are not acted upon by fiscal incentives. In this respect, the aims to be achieved through financial incentives are various macroeconomic objectives such as increasing the investments in the country, ensuring economic growth and development, increasing employment, struggle with economic conjuncture, attracting foreign capital.
\end{abstract}

$\begin{array}{ll}\text { Keywords } & ; \text { Financial Incentives, Investment, Development } . \\ \text { Jel Codes } & ; \text { E62, E22, O23. }\end{array}$

\footnotetext{
${ }^{1}$ Prof.Dr., Dokuz Eylül Üniversitesi, İ̈BF Maliye Bölümü, asuman.altay@deu.edu.tr

${ }^{2}$ Araş.Gör., Dokuz Eylül Üniversitesi, İIBF Maliye Bölümü, sahin-karabulut@ @otmail.com
} 


\section{Giriş}

Mali teşvikler genel olarak, ekonomideki birimleri belirli alanlarda daha iyi hale getirmek ve onların davranışlarını da bu yönde etkilemek için uygulanır. Mali teşvikler özellikle yatırım alanında uygulanarak, ekonomide yatırımlar aracılığı ile üretim hacminin, istihdam kapasitesinin ve büyüme hızının artması hedeflenir. Bunun yanında sektörlerin güçlenmesi, bölgeler arası dengesizliklerin giderilmesi ve ülkenin artan yatırımlar aracılığı ile küresel rekabet gücünün artırılması hedeflenir.

Mali teşvikler sonuçları itibariyle olumlu beklentilere yol açsa da, kamu sektörü açısından önemli mali yükleri de beraberinde getirir. Hükümetlerin mali yüklerini artırıcı teşviklere yönelmesinin temelinde, mali amaçlar dolaylı olarak yer almaktadır. Çoğunlukla bu teşvikler ekonomik ve sosyal amaçlı oluşturularak, iktisat politikası amaçlarına ulaşılmaya çalışılır. Özellikle yatırımların teşvik edilmesi, ekonomik büyüme ve uzun vadede kalkınmanın sağlanması ile istihdamın artırılması istenir. Bunun yanında küresel sermayenin ülkeye kazandırılması için de mali teşvikler söz konudur. Geçmiş yılların aksine küresel gelişmelerle birbirlerine bağımlı hale gelen ülkeler açısından mali teşvikler çok daha önemli hale gelmiştir. Ancak burada vurgulanması gereken nokta mali teşviklerin oluşturulması ve uygulanmasında ülkelerin bağımsız hareket edemeyeceğidir. Çünkü küreselleşen ticari ilişkilerde her ülkenin uyacağı küresel ilkelerin oluşturulması ile mali teşvik uygulamalarını da yönlendirmektedir.

Türkiye'de de yukarıda sözü edilen amaçlar doğrultusunda mali teşvik uygulamaları söz konusudur. Bölgeler arası teşviklerin yanında, sektör bazında mali teşviklerin de uygulandığı ülkemizde, özellikle yöresel teşviklerin son yıllarda daha ağırlıklı olduğu dikkat çekmektedir.

\section{Türkiye'de Uygulanan Mali Teşvikler}

Gelişmiş ve gelişmekte olan tüm ülkelerde esnaf ve zanaatkarlardan oluşan ticaret erbabı ile KOBI'lere yönelik bir çok teşvik uygulaması söz konusudur. Söz konusu teşviklerin başarılı olabilmesi için bu teşviklerin yöneldiği sektörlerin iyi belilenmesi oldukça önemlidir. BU açıdan KOBI'’lerin gelişmekte olan ülkelerde ekonomi içindeki önemlerinin çok büyük olması nedeniyle bu kesimin orta gelir gurubunda tutunamaması ve alt gelir grubuna kayması ekonomik istikrarı olumsuz şekilde etkileyecektir. (TESK, 2008:49). Bu nedenle hem bu kesime hem de nihai tüketici konumundaki kesime yönelik destek ve teşvik araçlarının geliştirilmesi son derece önem taşımaktadır.

Bu nedenle Osmanlı Devleti Dönemi'nde 1913 yılında çıkarılan Teşviki Sanayi Kanunu Muvakkati ile başlayan mali teşvik süreci Cumhuriyet Dönemi'nde ilk kez 1927 yilındaki Teşviki Sanayi Kanunu ile sisteme girmiştir. Söz konusu uygulama II. Dünya Savaşı'nın getirdiği mali yük nedeniyle devam ettirilememiş 1942 yılında yürürlükten kaldırıldıktan sonra devlet eliyle kalkınmacı bir politika benimsenmiştir.

Ekonomi politikalarının yönlendirilmesi amacı doğrultusunda ilk olarak 1946 yılında İvedili Sanayi Planı, 1947 yılında İktisadi Kalkınma Planı (Vaner Planı) hazırlanmıştır. 1948 yılında yapılan İktisat Kongresi'nde özel kesimin hükümet tarafından teşvikler yoluyla desteklenmesi gündeme gelmiş ancak 1950 yılına kadar herhangi bir özel yatırım teşviki uygulanmamıştır. Ancak 1951 yılına gelindiğinde 5821 sayılı "Yabancı Sermayeyi Teşvik Kanunu" kabul edilmiş ve 1954 yılında 6224 sayılı kanunla değiştirilmiştir. Sanayiye orta ve uzun vadeli kredi sağlamak amacıyla, bu dönemde teşvik konusunda önemli bir gelişme olan "Türkiye Sınai ve Kalkınma Bankası" kurulmuş ve ayrıca, 13.5.1953 tarih ve 6086 sayılı 
Turizm Endüstrisi Teşvik Kanunu ile turizm müesseseleri, 3.3.1954 tarih ve 6309 sayıl1 Maden Kanunu ile de maden aramaları teşvik edilmiştir. Söz konusu gelişmeler göz önüne alındığında 1950 ve 1960’lı yılların günümüzde uygulanan ekonomik teşviklerin şekillendiği dönem olduğu söylenebilir. (Tatar, 2011:28) .

1960'lı yıllardan itibaren planlı kalkınma dönemine tekrar geçilmiş ve kalkınma planlarıyla birlikte özel sektöre yönelik finansal teşvikler, vergi indirimleri, faiz indirimleri, yasal düzenlemeler, $\mathrm{AB}$ fonları, altyapı yatırımları gibi çeşitli mali teşvikler uygulamaya koyulmuştur. İlk defa 1963 yılında yürürlüğe giren kalkınma planlarının kronolojik sıralaması şu şekildedir:

- Birinci Beş Yıllık Kalkınma Planı

$1963-1967$

- İkinci Beş Yı1lık Kalkınma Planı

$1968-1972$

- Üçüncü Beş Yıllık Kalkınma Planı

1973 - 1977

- Dördüncü Beş Y1llık Kalkınma Planı

$1979-1983$

- Beşinci Beş Yı1lık Kalkınma Planı

$1985-1989$

- Altıncı Beş Yıllık Kalkınma Planı

$1990-1994$

- Yedinci Beş Yıllık Kalkınma Planı

$1996-2000$

- Sekizinci Beş Yı1lık Kalkınma Planı

$2001-2005$

- Dokuzuncu Kalkınma Planı

$2007-2013$

- Onuncu Kalkınma Planı

$2014-2018$

1980'li yıllara kadar hakim olan genel görüş nedeniyle Türkiye'de kalkınma planları daha ziyade ithal ikameci bir teşvik sistemiyle düzenlenmiş ancak 1980'lerde yükselen liberalizasyon politikaları sonucu bu tarihten itibaren ihracatı artırıcı teşvik tedbirleri alınarak kaynaklar bu alana kaydırılmıştır. Bu nedenle, ihracatta vergi iadesi, teşvik primi gibi direkt olarak ihracata bağlı nakit destekler bu dönemde verilmeye başlanmıştır. Ancak 1990’lı yıllarda imzalanan Gümrük Birliği Anlaşması sonucunda teşvik sistemi Avrupa Birliği ile uyumlaştırılarak nakit krediler büyük oranda kaldırılmış ve vergisel teşvikler ön plana çıkmaya başlamıştır (Leblebici, 2002:6) .

Bu kapsamda Türk Vergi Sistemi’nde mali teşvik özelliği taşıyan vergi istisna, muafiyet ve indirimlerinin bazıları şu şekildedir:

$\underline{\text { Gelir Vergisi }}$

- $\quad$ Esnaf muaflığı

- Dar mükellef ihracatçı muafiyeti

- $\quad$ Sergi ve panayır kazançları istisnası

- $\quad$ PTT acentaları kazançları istisnası

- Teknoloji geliştirme bölgelerinde faaliyet gösterenlerin kazançlarına ilişkin istisna

- Eğitim ve öğretim işletmelerinde kazanç istisnası

- $\quad$ Asgari geçim indirimi

- $\quad$ Teşvik ikramiye ve mükafatlarında istisnalar 
- $\quad$ Ar-ge ve destek personelinin ücretlerinde istisna

- Telif kazançları istisnası

- $\quad$ Ebe, sünnetçi, sağlık memuru, arzuhalci, rehber muaflığı

- $\quad$ Sergi ve panayır istisnas1,

- $\quad$ Menkul sermaye iradı, gayrimenkul sermaye iradı ve diğer kazanç ve iratlara ilişkin istisnalar

- Ar-ge harcamaları indirimi

- $\quad$ Eğitim ve sağlık harcamaları indirimi

\section{$\underline{\text { Kurumlar Vergisi }}$}

- İş̧irak kazançları istisnası

- $\quad$ Sermayeye ilave edilen kar payları ve fonlar

- Yurtdışında yapılan inşaat, onarım, montaj işleri ile teknik hizmetlerden sağlanarak genel sonuç hesaplarına intikal ettirilen kazançlar

- $\quad$ Kooperatiflerde risturn istisnas1

KDV ve ÖTV

- İhracat istisnas1

- Araçlar kıymetli maden ve petrol aramaları ile ulusal güvenlik harcamaları ve yatırımlarda istisna

- $\quad$ Taşımacıllı istisnası

- İthalat istisnas1

- $\quad$ Teknoloji geliştirme bölgelerindeki bazı teslim ve hizmetlere ilişkin istisna

Türkiye'de vergi sistemi içerisine yerleşmiş teşvik mekanizması bu şekilde olmakla birlikte, teşvik araçlarının birçoğunun yatırımlara tahsis edildiği görülmektedir. Bu doğrultuda, yeni iş olanakları oluşturulmasıyla işsizliğin düşürülmesi, özel yatırımlarda artışın sağlanması ve bölgesel gelişmişlik dengesizliklerinin azaltılması amacıyla çeşitli yatırım teşvikleri uygulanmıştır. Türkiye' de uygulanan teşvik sisitemi 2009 yllında yeniden düzenlenmiş ve bu sistem genişletilerek daha fazla yatırım alanının teşvikten yararlanması planlanmışısır. $\mathrm{Bu}$ kapsamda, rekabetin artırılması, yeni istihdam olanaklarının oluşturulması, ithalat ve ihracatta rekabetin geliştirilmesi gibi alanlar öncelikli olarak ele alınmıştır. 2012 yılında gündeme gelen yeni teşvik sistemi de önceki uygulamaya benzer özellikler göstermiş ve teşvike konu olan yatırımlarda kullanılacak araçlar Tablo 1'de verilmiştir. 2012 yılından itibaren uygulanan yeni teşvik sistemi temelde, gelişmemiş bölgelerde gerekli yatırımların ve kalkınmanın sağlanması ile stratejik ve teknolojik dönüşümü sağlayacak yatırımların desteklenmesi amaçlarını taşımaktadır. Diğer yandan 2016 yılında yeniden ele alınan teşvik sistemi önceki uygulamalardan farklı olarak proje tabanlı yatırımların teşvik edilmesini de gündeme getirmiştir. Ayrıca önceki teşvik uygulamalarının kapsamında yer almayan enerji ve ücret desteği de yine bu yıldan itibaren teşvik araçları kapsamına girmiştir (Yılmaz, 2016:1-2). 
Tablo 1 - Türkiye'de Son Y1llarda Uygulanan Teşvik Programları

\section{Teşvik Kapsamı}

\begin{tabular}{|c|c|c|}
\hline 2009 & 2012 & 2016 \\
\hline Türkiye Geneli & Türkiye Geneli & Yatırımlar Proje \\
\hline \multicolumn{3}{|c|}{ Teşvik Araçları } \\
\hline 2009 & 2012 & 2016 \\
\hline Vergi İndirimi & Vergi İndirimi & Vergi İndirimi \\
\hline Yatırım Yeri Tahsisi & Yatırım Yeri Tahsisi & Yatırım Yeri Tahsisi \\
\hline Gümrük Vergisi Muafiyeti & Gümrük Vergisi Muafiyeti & Gümrük Vergisi Muafiyeti \\
\hline KDV İstisnası & KDV İstisnası & KDV İstisnası \\
\hline Faiz Desteği & Faiz Desteği & Faiz Desteği \\
\hline \multirow[t]{4}{*}{ Sigorta Primi Desteği } & Sigorta Primi Desteği & Sigorta Primi Desteği \\
\hline & Gelir Vergisi Stopaj Desteği & Gelir Vergisi Stopaj Desteği \\
\hline & & Enerji Desteği \\
\hline & & Ücret Desteği \\
\hline
\end{tabular}

Kaynak: (Y1lmaz, 2016:1).

Türkiye'de yatırımlara yönelik en kapsamlı verilen teşvikler 15 Haziran 2012'de kabul edilerek 19 Haziran 2012'de Resmi Gazete'de yayınlanan 2012/3305 sayıl1 "Yatırımlarda Devlet Yardımları Hakkında Karar"da düzenlenmiştir. Söz konusu kararda uygulama zamanı boyunca şu ana dek $13 \mathrm{kez}$ düzenleme yapılmıştır. Söz konusu düzenlemeler Tablo 2'de görülmektedir. 
Tablo 2 - 2012/3305 Sayılı Kararda Gerçekleştirilen Değişiklikler

\begin{tabular}{|c|c|c|c|}
\hline \multicolumn{2}{|c|}{ Bakanlar Kurulu Kararı } & \multicolumn{2}{|c|}{ Yayımlandığı Gazete } \\
\hline Karar Tarihi & Karar Sayısı & Yayın Tarihi & Gazete Sayısı \\
\hline 15.06.2012 & $2012 / 3305$ & 19.06.2012 & 28328 \\
\hline \multicolumn{4}{|c|}{ Bakanlar Kurulu Kararında Değiş̧iklik Yapan Düzenlemeler } \\
\hline 02.10 .2012 & $2012 / 3802$ & 13.10 .2012 & 28440 \\
\hline 28.01.2013 & $2013 / 4288$ & 15.02 .2013 & 28560 \\
\hline 27.05.2013 & $2013 / 4763$ & 30.05 .2013 & 28662 \\
\hline 27.01.2014 & $2014 / 6058$ & 09.05 .2014 & 28995 \\
\hline 30.06.2014 & $2014 / 6588$ & 06.08 .2014 & 29080 \\
\hline 15.12.2014 & $2014 / 7273$ & 05.03 .2015 & 29286 \\
\hline 16.03.2015 & $2015 / 7496$ & 08.04.2015 & 29320 \\
\hline 20.08.2015 & $2015 / 8050$ & 27.08.2015 & 29458 \\
\hline 09.11 .2015 & $2015 / 8216$ & 19.11.2015 & 29537 \\
\hline 29.02.2016 & $2016 / 8715$ & 08.04 .2016 & 29678 \\
\hline 07.09.2016 & 2016/9139 & 05.10 .2016 & 29848 \\
\hline 13.02.2017 & 2016/9917 & 22.02 .2017 & 29987 \\
\hline 24.04.2017 & $2017 / 10111$ & 03.05.2017 & 30055 \\
\hline
\end{tabular}

Kaynak: 2017/10111 Sayılı Bakanlar Kurulu Kararı.

2012 yılından itibaren uygulanan yatırım teşvik mekanizması ile ulaşılmak istenen amaçlar 2012/3305 say1lı kararda:

- Kalkınma planları ve yıllık programlarda öngörülen hedefler doğrultusunda tasarrufların katma değeri yüksek yatırımlara yönlendirilmesine,

- Üretim ve istihdamın artırılmasına,

- Uluslararası rekabet gücünü artıracak ve araştırma- geliştirme içeriği yüksek bölgesel ve büyük ölçekli yatırımlar ile stratejik yatırımların özendirilmesine,

- Uluslararası doğrudan yatırımların artırılmasına,

- Bölgesel gelişmişlik farklılıklarının azaltılmasına, 
- Kümelenme ve çevre korumaya yönelik yatırımlar ile araştırma ve geliştirme faaliyetlerinin desteklenmesine ilişkin usul ve esasları belirlemek olarak ifade edilmiştir.

\section{Türkiye'de Yatırım Teşvik Sistemi}

2012 yılında yatırımlar alanında yapılan düzenleme ile bu amaçla verilecek teşvikler 5 ana başl1kta toplanmıştır ve bu teşvik sistemi Şekil 1'de gösterildiği gibidir.
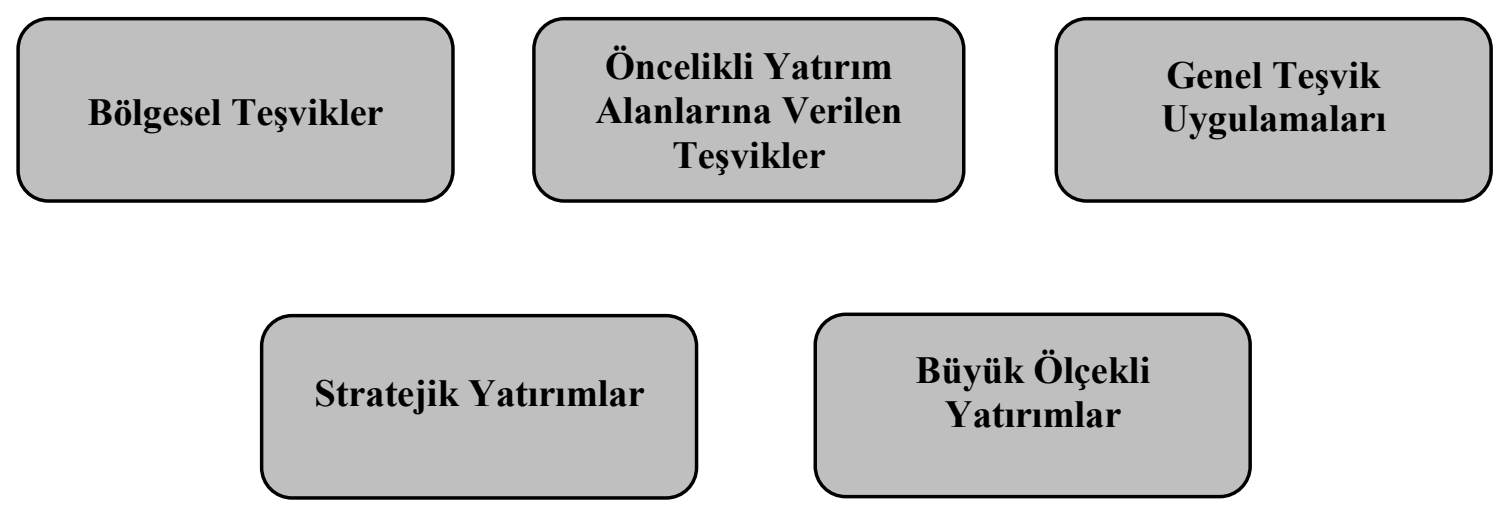

Şekil 1 - Türkiye'de Yatırım Teşvik Sistemi

\subsection{Bölgesel Teșvikler}

Bölgesel teşvik uygulamaları şehirler arasında dengeli bir gelişmişlik düzeyi yakalamak amacıyla, belirlenen gelişmişlik düzeylerine göre farklı büyüklüklerde yatırımların teşvik edilmesini amaçlamaktadır. Şehirlerin gelişmişlik düzeyleri Kalkınma Bakanlığı tarafından yapılan "İllerin ve Bölgelerin Sosyo-Ekonomik Gelişmişlik Sıralaması Araştırması (SEGE2011)"na göre belirlenmiş ve bu kapsamda iller 6 farklı bölgeye ayrılmıştır. Söz konusu çalışmaya göre illerin sıralaması Tablo 3’te verilmiştir.

Tablo 3 - SEGE 2011'e Göre İllerin Gelişmişlik Düzeyleri

\begin{tabular}{|c|c|c|c|c|c|}
\hline 1. Bölge & 2. Bölge & 3. Bölge & 4. Bölge & 5. Bölge & 6. Bölge \\
\hline Ankara & Adana & Balıkesir & Afyonkarahisar & Adiyaman & Ağr1 \\
\hline Antalya & Aydın & Bilecik & Amasya & Aksaray & Ardahan \\
\hline Bursa & Bolu & Burdur & Artvin & Bayburt & Batman \\
\hline Eskişehir & Çanakkale & Gaziantep & Bartın & Çankırı & Bingöl \\
\hline İstanbul & Denizli & Karabük & Çorum & Erzurum & Bitlis \\
\hline
\end{tabular}




\begin{tabular}{|c|c|c|c|c|c|}
\hline İzmir & Edirne & Karaman & Düzce & Giresun & Diyarbakır \\
\hline Kocaeli & Isparta & Manisa & Elazı $\breve{g}$ & Gümüşhane & Hakkari \\
\hline \multirow[t]{10}{*}{ Muğla } & Kayseri & Mersin & Erzincan & Kahramanmaraş & Iğdır \\
\hline & Kirklareli & Samsun & Hatay & Kilis & Kars \\
\hline & Konya & Trabzon & Kastamonu & Niğde & Mardin \\
\hline & Sakarya & Uşak & Kırıkkale & Ordu & Muş \\
\hline & Tekirdağ & Zonguldak & Kırşehir & Osmaniye & Siirt \\
\hline & Yalova & & Kütahya & Sinop & Şanlıurfa \\
\hline & & & Malatya & Tokat & Şırnak \\
\hline & & & Nevşehir & Tunceli & Van \\
\hline & & & Rize & Yozgat & \\
\hline & & & Sivas & & \\
\hline 8 İL & 13 İL & 12 İL & 17 İL & 16 IL & 15 İL \\
\hline
\end{tabular}

Söz konusu kararın ekinde bölgesel desteklerden faydalanabilecek sektörler ve bölgeler itibariyle asgari yatırım tutarları veya kapasiteleri belirtilmiş ve bu limitleri aşan yatırımların bölgesel teşvik uygulamalarından yararlanabileceği hükmü getirilmiştir. Bu kapsamda yatırımlar çeşitli oran ve miktarlarda KDV İstisnası, gümrük vergisi muafiyeti, vergi indirimi, sigorta primi işveren hissesi desteği, faiz desteği (3.,4.,5. ve 6. bölgelerde), yatırım yeri tahsisi, sigorta primi desteği (6. bölgede), gelir vergisi stopajı desteği (6. bölgede)'nden yararlanabilecektir.

\section{2. Öncelikli Yatırım Alanlarına Verilen Teşvikler}

2012 yılında başlatılan yeni yatırım teşvik sisteminde Türkiye'de geliştirilesi çncelikli olan sektörler belirlenmiş ve bu kapsama alınan sektörlere yapılacak yatırımların teşvik edilmesi kararlaştırılmıştır. KDV istisnası, gümrük vergisi muafiyeti, vergi indirimi, sigorta primi işveren hissesi desteği, yatırım yeri tahsisi, faiz desteği gibi teşviklerden yararlanabilecek öncelikli olarak belirlenen sektörler şu şekilde verilmiştir:

- Kültür ve Turizm Koruma ve Gelişim Bölgelerinde veya termal turizm konusunda bölgesel desteklerden yararlanabilecek nitelikteki turizm konaklama yatırımları,

- Madencilik yatırımları,

- Demiryolu ve denizyolu ile yük veya yolcu taşımacılığına yönelik yatırımlar, 
- Savunma sanayi yatırımları,

- Otomotiv, uzay veya savunma sanayine yönelik test merkezleri, rüzgâr tüneli ve bu mahiyetteki yatırımlar,

- Asgari $50.000 \mathrm{~m} 2$ kapalı alana sahip uluslararası fuar alanı yatırımları,

- Özel sektör tarafından gerçekleştirilecek olan kreş ve gündüz bakımevleri ile okul öncesi eğitim, ilkokul, ortaokul ve lise eğitim yatırımları,

- Bilim, Sanayi ve Teknoloji Bakanlığı, TÜBİTAK ve KOSGEB tarafından desteklenen Ar-Ge projeleri neticesinde geliştirilen ürünlerin veya parçaların üretimine yönelik yatırımlar,

- Motorlu kara taşıtları ana sanayinde gerçekleştirilecek asgari 300 milyon TL tutarındaki yatırımlar ve asgari 75 milyon TL tutarındaki motor yatırımları ile asgari 20 milyon TL tutarındaki motor aksamları, aktarma organları/aksamları ve otomotiv elektroniğine yönelik yatırımlar,

- 3213 sayılı Maden Kanunu'nda tanımlanmış 4-b grubunda yer alan madenlerin girdi olarak kullanıldığı elektrik üretimi yatırımları,

- Mevcut imalat sanayi tesislerinde gerçekleştirilecek enerji verimliliğine yönelik yatırımlar,

- Atık 1sıdan geri kazanım yolu ile elektrik üretimine yönelik yatırımlar,

- Asgari 50 milyon TL tutarındaki sıvılaştırılmış doğalgaz (LNG) yatırımları ve yer altı doğalgaz depolama yatırımları,

- Karbon elyaf üretimine veya karbon elyaf üretimi ile birlikte olmak kaydıyla karbon elyaftan mamul kompozit malzeme üretimine yönelik yatırımlar,

- Ekonomik İşbirliği ve Kalkınma Teşkilatı (OECD) teknoloji yoğunluk tanımına göre yüksek teknolojili sanayi sınıfinda yer alan ürünlerin üretimine yönelik yatırımlar,

- Maden Kanunu'na istinaden düzenlenmiş geçerli Arama Ruhsatı veya Sertifikasına sahip yatırımcıların ruhsatlı sahalarında yapacağı maden arama yatırımlar1.

- Yenilenebilir enerji üretimine yönelik türbin ve jeneratör imalatı ile rüzgâr enerjisi üretiminde kullanılan kanat imalatı yatırımları.

- Direkt soğutmalı slab döküm ve sıcak haddeleme yöntemi ile alüminyum yassı mamul üretimine yönelik entegre yatırımlar.

- Lisanslı depoculuk yatırımları.

- Nükleer enerji santrali yatırımları. 


\subsection{Stratejik Yatırımlara Yönelik Teșvikler}

2012/3305 sayılı Bakanlar Kurulu Karar'da yer alan üçüncü teşvik mekanizması da stratejik yatırımların artırılmasına yöneliktir. Bu kapsamda desteklenecek yatırımların stratejik olarak ifade edilmesinin sebebi ithalat bağımlılığı yüksek olan ara malı ve nihai ürünleri ikame edecek üretimin yapılmasını sağlama amacından kaynaklanmaktadır. İthal ikamesine yönelik katma değeri yüksek ürünlerin yurtiçi üretiminin artırılması hiç şüphesiz ki cari denge üzerinde oldukça olumlu etki yapacaktır. Ancak stratejik yatırımlara yönelik teşviklerden yararlanabilecek yatırımların 4 temele şartı taşıması aranmaktadır. Buna göre:

- Sabit yatırım miktarı 50 milyon TL'den fazla olan,

- Yatırım sonrası üretilecek ürünün ithalat miktarı yurtiçi üretimden fazla olan,

- Rafineri ve petrokimya yatırımları hariç olmak üzere yatırım sonucunda yüzde 40'tan fazla katma değer oluşturan,

- Üretilecek ürünün son bir y1lda en az 50 milyon Dolar'lık ithalat değeri olan yatırımlar stratejik yatırımlara yönelik teşvikler kapsamına girmektedir.

Bunların dışında öncelikli yatırımlar kapsamında sabit yatırım tutarları 3 milyoar TL'yi aşan yatırımlar stratejik yatırm olarak kabul edilmiş ve bu yatırımlara verilecek faiz desteğinin 700 bin TL'yi aşamayacağı karara bağlanmıştır. Stratejik yatırımlara yönelik teşvikler KDV istisnas1, gümrük vergisi muafiyeti, vergi indirimi, sigorta primi işveren hissesi desteği, yatırım yeri tahsisi, kdv iadesi, sigorta primi desteği (6. bölge), gelir vergisi stopajı desteği (6. bölge) avantjlarından yararlanmaktadır.

\subsection{Büyük Ölçekli Yatırımlara Yönelik Teșvikler}

Türkiye'nin teknoloji ve AR-GE kapasitesini artırma ve uluslararası rekabet üstünlüğü elde etme amacına yönelik olarak bu amaçlara hizmet edecek 12 sektörün bölgesel gelişmişlik düzeyine göre farklı şekillerde teşvik edilmesi kararlaştırılmıştır. Bu amaçla, bölgesel yatırım teşvik uygulamalarından daha avantajlı olan Büyük Ölçekli Yatırımların Teşviki Uygulaması kullanılmaktadır. Yapılan bir yatırımın büyük ölçekli yatırım teşvikinden yararlanabilmesi için aşağıda sayılan sektörlerde ve minimum miktarlarda yatırım yapılmış olması ön şart olarak koşulmuştur (2012/2205 Say1lı BKK, Ek-3). Buna göre;

- Rafine edilmiş petrol ürünleri imalatına yapılan en az 1 milyar TL,

- Kimyasal madde ve ürünlerin imalatı, liman ve liman hizmetleri ile havalimanı ve motorlu kara taşıtları ana sanayiine yapılan en az 200 milyon TL,

- Motorlu kara taşıtları yan sanayi, demiryolu ve tramvay lokomotifleri ve/veya vagon imalatı, transit boru hattıyla taşımacılık hizmetleri, elektronik sanayi, tıbbi alet, hassas ve optik aletler imalatı, ilaç üretimi, hava ve uzay taşıtları ve/veya parçaları imalatı, makine imalatı ve nihai metal üretimine yönelik yapılan en az 50 milyon TL tutarındaki yatırımlar büyük ölçekli yatırımlar olarak değerlendirilmektedir. 


\subsection{Genel Teşvik Uygulamaları}

Genel teşvik uygulamaları diğer dört yatırım teşviki kapsamına girmediği halde 2012/3305 saylı BKK'da teşvik edilmeyecek yatırım konuları içinde de yer almayan projeleri belirli asgari yatırım koşullarını sağlaması durumunda uygulanan teşvik aracıdır. Söz konusu Karar'da teşvik edilmeyecek sektörler tarım, imalat, enerji, madencilik ve hizmetler alanında toplam 34 kalemde sayılmıştır. Yine aynı alanlardaki 20 sektörün ise genel teşvik uygulamalarından yararlanması belli şartlara bağlanmıştır.

\section{Türkiye'de Yatırım Teșvik Sisteminin Araçları}

Türkiye'de 2012 yılından itibaren yatırım teşvikleri tek çatı altında toplanmış ve 2012/3305 sayılı Bakanlar Kurulu Kararı ile yatırım teşviklerinin araçları 4. ve 17. maddeler arasında sayılmıştır. Buna göre Türkiye'de yatırımlara uygulanan teşvikler Şekil 2'de gösterilmiştir.

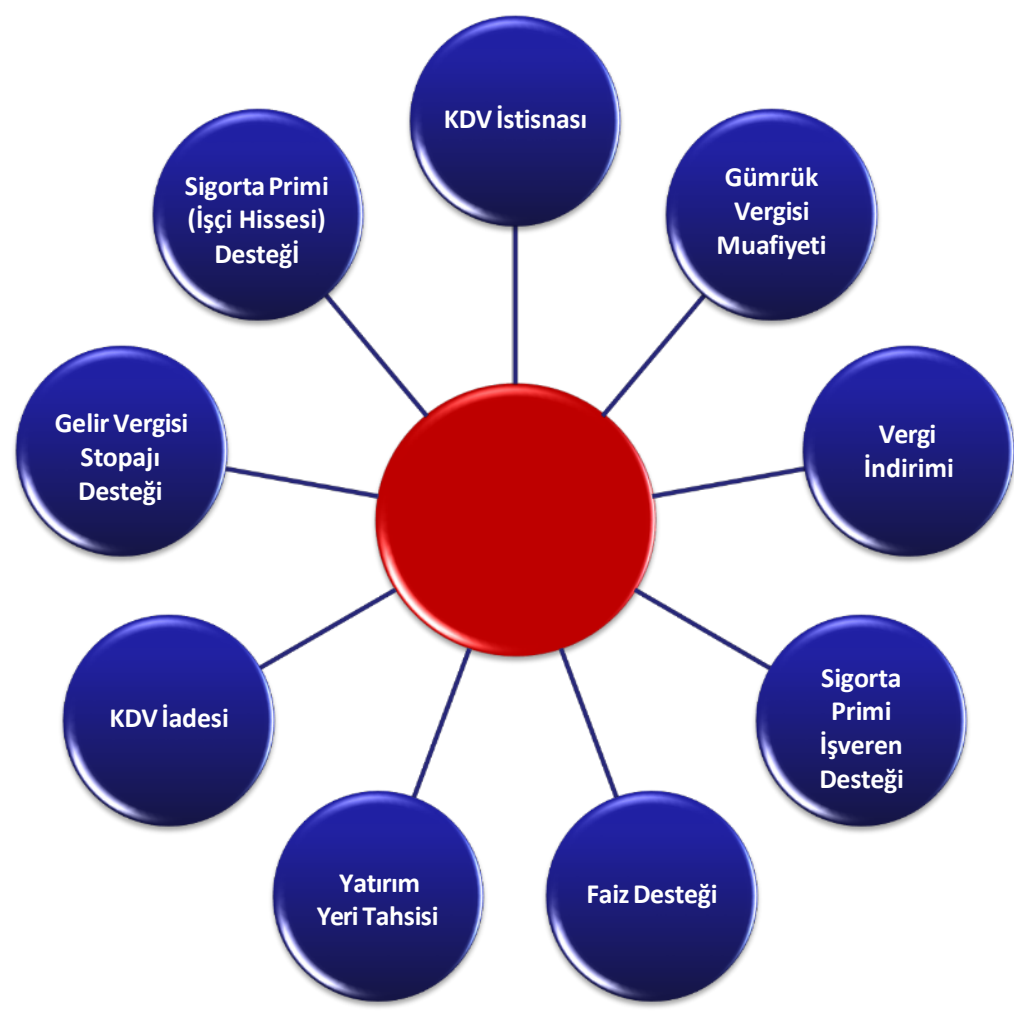

Şekil 2 - Türkiye'de Yatırım Teşvik Sistemi Araçları

Kaynak: Türkiye Cumhuriyeti Ekonomi Bakanlığı, www.ekonomi.gov.tr.

Türkiye'de yatırımlara uygulanan teşviklerin verildiği Şekil 2'ye göre, toplam 9 adet teşvik aracı kullanılmaktadır. Bu araçlar incelendiğinde bunların 5 tanesi (KDV istisnası, gümrük vergisi muafiyeti, vergi indirimi, KDV iadesi, gelir vergisi stopaj1) vergisel teşviklerden, 2 tanesi (sigorta primi işveren hissesi desteği ve sigorta primi işçi hissesi desteği) sosyal güvenlik desteklerinden, 1 tanesi (faiz desteği) mali desteklerden, 1 tanesi ise (yatırım yeri tahsisi) fiziki desteklerden oluşmaktadır. 
$\mathrm{Bu}$ araçlardan $K D V$ istisnası ele alındığında, bu uygulamada yatırım teşvik belgesine sahip olunması durumunda bu kapsamda ithal edilen ya da yerli üretimden satın alınan yatırım malı, makine ve teçhizat ile belge kapsamındaki yazılım ve gayri maddi hak satış ve kiralamaları katma değer vergisinden istisna tutulmuştur.

Gümrük vergisi konusunda, 2012/3305 say1lı BKK'nın 9. Maddesinde “Teşvik belgesi kapsamındaki yatırım malı makine ve teçhizatın ithali, otomobil ve hafif ticarî araç yatırımlarında yatırım dönemi içerisinde kalmak kaydiyla monte edilmemiş haldeki aksam ve parçaların ithali, gemi ve elli metrenin üzerindeki yat inşa yatırımlarında tekne kabuğu ithali yürürlükteki Ithalat Rejimi Kararı gereğince ödenmesi gereken gümrük vergisinden muaftır". hükmü getirilmiştir.

Yatırım teşvik sistemine göre büyük ölçekli yatırımlar, stratejik yatırımlar ve bölgesel teşvik uygulamaları kapsamına giren yatırımların farklı oran ve miktarlarda gelir ve kurumlar vergisinde indirimli oranlara tabi tutulacağı belirtilmiştir. $\mathrm{Bu}$ yatırımlara uygulanacak indirimli vergi oranları ve süreleri belirlenirken sabit yatırım tutarının belli bir yüzdesi kıstas alınmıştır ve bu kriterler 2012/3305 sayılı kararda verilmiştir. Vergi indirimi konusunda sağlanan bir diğer avantaj ise yatırımcının diğer faaliyetlerinden elde ettiği gelirler için gelir ve kurumlar vergisinden indirimli olarak yararlanmasıdır. Buna göre, yatırımcının diğer gelir ve kazançları yatırıma katkı tutarının belli bir oranını aşmamak kaydıyla bir vergi avantajı saylayacaktır.

Sigorta Primi İşveren Hissesi Desteği'ne göre ise, yatırımlar sonucunda oluşturulan ilave istihdam dolayısıyla yatırımcıya düşen sigorta pirimi işveren hissesinin asgari ücrete denk gelen kısmının Ekonomi Bakanlığı tarafından belli bir süre üstlenilmesi söz konusudur. $\mathrm{Bu}$ destek Bölgesel, Büyük Ölçekli ve Stratejik Yatırımlar kapsamında verilmektedir.

Yatırımlara sağlanan mali desteklerden bir diğeri de Faiz Desteği'dir. Bu kapsamda minimum 1 yıl vadeye sahip olan yatırım kredileri için sabit yatırımın yüzde 70'lik kısmına denk gelen faiz ya da kar payının bir kısmının Ekonomi bakanlığı tarafından karşılanması söz konusudur. Bu teşvik aracı, stratejik yatırımlar, Ar-ge yatırımları, çevre yatırımları ve üçüncü, dördüncü, beşinci ve altıncı bölgelerle sınırlı olma üzere bölgesel teşvik uygulamaları kapsamında kullanılmaktadır.

Diğer yandan büyük ölçekli yatırımlar, stratejik yatırımlar ve bölgesel desteklerin teşviki amacıyla bu alanlarda yapılacak yatırımlar için Bedelsiz Yatırım Yeri Tahsisi yapılabileceği 2012/3305 sayılı BKK ile kararlaştırılmıştır.

Diğer teşvik araçlarına göre daha dar kapsamlı olan KDV İadesi uygulamasına göre Stratejik Yatırımlar kapsamında sabit yatırım tutarı 500 milyon TL'yi geçen bina-inşaat harcamaları için ödenmiş olan Katma Değer Vergisi'nin iade edilmesi söz konusudur.

Yalnızca 6. bölgede yapılacak yatırımlar ile sınırlı olmak üzere bu bölgede yapılacak yatırım sonucunda sağlanan ilave istihdam için ödenecek gelir vergisi stopajının asgari ücrete denk gelen bölümü 10 yıl süreyle Gelir Vergisi Stopajı Desteği kapsamında terkin edilecektir.

6. bölgede yapılacak yatırımlara uygulanacak bir diğer destek türü ise Sigorta Primi (İş̧i Hissesi) Desteği'dir. Bu kapsamda bu bölgede yapılan yatırım sonucunda oluşturulan ilave istihdam için ödenecek sigorta primi işçi payının asgari ücrete denk gelen bölümünün 1o y1l boyunca Ekonomi Bakanlığı tarafından karşılanması kararlaştırılmıştır. Ancak bu uygulamaya genel teşvik uygulaması kapsamında yapılacak yatırımlar dahil edilmemiştir. 


\section{Sonuç ve Değerlendirme}

Tarihsel olarak bakıldığında Osmanlı Devleti’nin son döneminde 1913 yılında çıkarılan Teşviki Sanayi Kanunu Muvakkati ile başlayan mali teşvik sürecinin Türkiye Cumhuriyeti Devletinin kuruluşundan günümüze kadar devam ettiği söylenebilir. Zaman zaman savaşlar ve olağanüstü olaylar nedeniyle kesintiye uğrasa da özellikle yatırımların mali açıdan teşvik edilmesi sistemsel olarak sürdürülmüştür.

1951 y1lında 5821 sayılı "Yabancı Sermayeyi Teşvik Kanunu”'nun kabul edilmesi ile (1954 yılında 6224 sayılı kanunla değiştirilmiştir) ülkenin yabancı yatırım ve yabancı yatırımcıya açılarak, yatırımların artırılması ve yeni istihdam alanlarının oluşturulması amaçlanmıştır. Ayrıca yine bu dönemde, sanayiye orta ve uzun vadeli kredi sağlamak amacıyla, teşvik konusunda önemli bir gelişme olan "Türkiye Sınai ve Kalkınma Bankası" kurulmuş ve 13.5.1953 tarih ve 6086 sayılı Turizm Endüstrisi Teşvik Kanunu ile turizm müesseseleri, 3.3.1954 tarih ve 6309 sayılı Maden Kanunu ile de maden aramaları teşvik edilmiştir.

Yukarıda sözü edilen 1950-1960 dönemi değerlendirildiğinde, teşviklerle özel sektörün yatırım payının artırılmaya çalışıldığı ve o günden günümüze kadar devam eden söz konusun teşvik sisteminin alt yapısının hazırlandığı ileri sürülebilir. 1960'lı yıllardan itibaren hazırlanmaya başlanılan beş yıllık kalkınma planlarında da özel sektöre yönelik finansal teşvikler, vergi indirimleri, faiz indirimleri, yasal düzenlemeler, $\mathrm{AB}$ fonları, altyapı yatırımları gibi çeşitli mali teşvikler uygulamaya koyulmuştur.

1980'li yılların özellikle ilk yarısı Türkiye'de siyasi ve ekonomik bir çok değişikliklere sahne olmuştur. Yükselen liberal piyasa ekonomisi, serbestleşme eğilimleri ve dünya piyasaları ile entegrasyon hareketleri özellikle ihracatta mali teşvik sisteminin oluşturulması ile sonuçlanmıştır. İhracatın artırılması için getirilen mali teşvikler arasında yer alan başta Katma Değer Vergisi iadeleri ve diğer ihracat destekleri ile kamu kaynaklarının önemli bir kısmı bu uğurda aktarılmıştır. 1990'lı yıllar ise dış ticarette liberalizasyonun artırılmaya çalışıldığı yıllara olmuş ve 1995 yılında AB ile "Gümrük Birliğì" anlaşması imzalanmıştır. $\mathrm{Bu}$ dönemde mali teşvikler anlaşma kapsamında düzenlenmeye çalışılmıştır.

Genel olarak değerlendirildiğinde, bölgeler arası sosyo-ekonomik gelişmişlik farklarının fazla olduğu ülkemizde, planlı dönemin başından günümüze, ekonomik gelişmenin hızlandırılması için mali teşviklerden yararlanılmaktadır. Nitekim mevcut teşvik sistemi temelde bölgesel önceliklere dayandırılmaktadır. Bununla birlikte, eğitim, sağlık ve alt yapı yatırımları gibi sosyal amaçlı yatırımları da destekleyebilecek biçimde sektörel ayrıma da önem verildiği görülmektedir. Destek sistemi kapsamında, özel kesime doğrudan kaynak aktarımı sayılabilecek destekler yerine, piyasa mekanizması çerçevesinde oluşturulan yatırım konularının vergi muafiyet ve istisnaları yolu ile desteklendiği bir sistemin tercih edildiği dikkati çekmektedir.

Mali teşviklerin, vergi muafiyet ve istisnaları, düşük faizli kredi ya da hibe yardımları yanına, enerji indirimleri, arsa tahsisi ve finansman kolaylıkları sağlayan bazı yöntemlerden de oluştuğu söylenebilir. Uygulamada genel olarak, söz konusu teşvik araçlarından biri ya da birkaçının bir arada kullanılması mümkündür. Türkiye'de de tercih edilen bu yöntem ile ekonomiye doğrudan enjekte edilen mali teşvik ve diğer kolaylıklar ile kısa sürede olumlu etkiler ortaya çıkabilmektedir. 


\section{KAYNAKÇA}

2012/3305 Karar Sayılı Bakanlar Kurulu Kararı. (2012). Yatırımlarda Devlet Yardımları Hakkında Karar, Resmi Gazete'de Yayınlanma Tarihi: 19.06.2012, 28328 Sayılı Resmi Gazete.

2017/10111 Karar Sayılı Bakanlar Kurulu Kararı.(2017) Yatırımlarda Devlet Yardımları Hakkında Kararda Değişiklik Yapılmasına Dair Karar, Resmi Gazete'de Yayınlanma Tarihi: 03.05.2017, 30055 Sayılı Resmi Gazete.

LEBLEBİCI, F. (2002). Devlet Yardımları Uygulamasının Maliyeti ve Ekonomik Göstergelerle Mukayesesi, Devlet Planlama Teşkilatı, Yayın No: 2663, Ankara.

TATAR, G. (2011). Türkiye'de Maliye Politikası Aracı Olarak Teşvik Politikaları ve Çukurova Örneği (Yüksek Lisans Tezi), Çukurova Üniversitesi Sosyal Bilimler Enstitüsü, Adana.

TESK. (2008). Esnaf ve Sanatkar Raporu Mevcut Durum Sorunlar Öneriler, Ankara.

Türkiye Cumhuriyeti Ekonomi Bakanlığı. www.ekonomi.gov.tr, (09.08.2017).

Türkiye Cumhuriyeti Kalkınma Bakanlığı, "İllerin ve Bölgelerin Sosyo-Ekonomik Gelişmişlik Sıralaması Araştırması (SEGE) 2011”, (2013). Bölgesel Gelişme Ve Yapisal Uyum Genel Müdürlüğü, Ankara.

YILMAZ, E. (2016). “Türkiye'de Son Dönemde Uygulamaya Konan Teşvik Sistemlerinin Temel Özellikleri”, Türkiye Cumhuriyet Merkez Bankası Merkezin Güncesi, 1 Aralık 2016, https://tcmbblog.org/tr/turkiyede-son-donemde-uygulamaya-konantesvik-sistemlerinin-temel-ozellikleri/, (08.08.2017). 